\title{
Interleukin-1 receptor antagonist levels in gingival crevicular fluid and serum in nonsmoking women with preterm low birth weight and intrauterine growth retardation
}

\author{
Nezahat Arzu Kayar ${ }^{1}$, Nilgun Ozlem Alptekin², Seyfullah Haliloglu ${ }^{3}$
}

Correspondence: Dr. Nilgun Ozlem Alptekin

Email:noalptekin@baskent.edu.tr
'Department of Periodontology, Oral and Dental Health Center, The Ministry Health of Turkey, Antalya, Turkiye, 2Department of Periodontology, Faculty of Dentistry, Baskent University, Ankara, Turkiye,

${ }^{3}$ Department of Biochemistry, Faculty of Veterinary,

Selcuk University, Konya, Turkiye

\section{ABSTRACT}

Objective: The aim of this study was to evaluate interleukin (IL)-1 $\beta$ and IL-1 receptor antagonist (IL-1ra) levels in gingival crevicular fluid (GCF) and serum (S) in nonsmoking women with normal birth (NB), preterm low birth weight (PLBW), and intra-uterine growth retardation (IUGR). Materials and Methods: In this unmatched case-control study design, 64 women with $\mathrm{NB}, 45$ women with PLBW, and 47 women with IUGR were recruited within $24 \mathrm{~h}$ delivery. Clinical periodontal parameters were recorded. IL-1 $\beta$ and IL-1ra levels in GCF (pg/30 s) and serum ( $\mathrm{pg} / \mathrm{ml}$ ) of were evaluated using commercial enzyme immunoassay and ELISA kits. Results: Greater pocket depth and clinical attachment loss were observed in PLBW and IUGR women than in NB women $(P<0.05)$. The total amounts of IL-1 ra and IL- $\beta$ of GCF were higher levels in NB women than PLBW and IUGR women $(P<0.05)$. The lowest total amount of IL-1 ra of GCF was found in IUGR women $(P<0.05)$. The concentrations of IL-1 ra in serum samples were not statistically significant for any of the study groups $(P>0.05)$. Conclusion: It can be suggested that worse periodontal conditions and the low levels of IL-1ra in GCF may be an important factor in adverse pregnancy outcomes.

Key words: Cytokine(s), gingival crevicular fluid, periodontal-systemic disease interactions, serum

\section{INTRODUCTION}

Low birth weight (LBW), an adverse pregnancy outcome, is a weight of $<2500 \mathrm{~g}$ at birth and a major determinant of neonatal infant morbidity and mortality, and contributes to nearly half of all severe long-term, birth related, neurological morbidities, including cerebral palsy. ${ }^{[1]}$ There are two categories of LBW: (1) Preterm low birth weight (PLBW) is defined as a delivery at a gestational age $<37$ weeks. (2) Intra-uterine growth retardation (IUGR) may be full-term but is underweight. Over the past 20 years, evidence has been accumulated indicating that IUGR affects normal development of the kidneys and vascular system, thereby increasing the likelihood of hypertension and/or cardiovascular diseases. ${ }^{[2,3]}$

Even though maternal risk factors including age, height, weight, socioeconomic status, ethnicity, smoking, alcohol, nutritional status, chronic infection and stress, these factors are not present in approximately $50 \%$ of cases and a significant proportion of LBW is a result of unknown etiology. ${ }^{[4]}$ The one of the hypotheses that infection remote from the fetal-placental unit may influence LBW has led to an increased awareness of the potential role of chronic bacterial infections elsewhere in the body. Periodontal disease is a chronic inflammatory process

\footnotetext{
How to cite this article: Kayar NA, Alptekin NO, Haliloglu S. Interleukin-1 receptor antagonist levels in gingival crevicular fluid and serum in nonsmoking women with preterm low birth weight and intrauterine growth retardation. Eur J Dent 2015;9:109-16. 
mostly caused by infection by Gram-negative bacterial biofilm harboring periodontal pockets. Thus, the lipopolysaccharide of such bacterium induces the production of pro-inflammatory cytokines, which in turn cause the destruction of hard and soft periodontal tissues. Although periodontitis is localized to the periodontal tissues, a low-grade bacteremia or circulating inflammatory mediators have deleterious effects on distant tissues, like pregnant womb. ${ }^{[5]}$ When chronic high levels of cytokines and prostaglandins are present in the amniotic fluid, they may lead to IUGR, spontaneous preterm labor, premature rupture of membranes, and preterm birth. ${ }^{[6]}$

There is increasing evidence to suggest that the presence of periodontal infection may present a systemic challenge sufficient to initiate the onset of premature labor as a source of lipopolysaccharide and/or through stimulation of pro-inflammatory cytokines. ${ }^{[5,7,8]}$ Interleukin (IL) $-1 \beta$ was the first cytokine implicated in the onset of the labor in the presence of infection. ${ }^{[9]}$ Several studies report associations of adverse pregnancy outcome with higher gingival crevicular fluid (GCF) levels of prostaglandin $\mathrm{E}\left(\mathrm{PGE}_{2}\right)^{[5]}$ and IL-1 $\beta,{ }^{[7,10]}$ elevated amniotic fluid concentrations of PGE, IL-1 $\beta$, and IL- $8^{[11]}$ and measured serum IL-1 $\beta$ and IL- $8 .{ }^{[12]}$ In an investigation by Noack et al. ${ }^{[13]}$ the gingival crevice fluid IL-1 $\beta$ level was not different in the PLBW group when compared to normal birth (NB) group.

Interleukin-1 receptor antagonist (IL-1ra) is an interesting cytokine, which binds to the host cell surface using the receptors as the pro-inflammatory IL-1 $\alpha$ and IL-1 $\beta$, thereby inhibiting the signal transduction by blocking the receptors. IL-1ra may play an important role in regulating the local effect of IL-1 in inflammatory periodontal disease. ${ }^{[14,15]}$

The present study was planned to investigate the possible effects of inflammatory mediators such as IL-1 $\beta$ and IL-1ra from the periodontal reservoir on the fetoplacental unit. It can be hypothesized that local production of IL-1 $\beta$ and IL-1ra in the periodontal area may also result in an elevated serum concentration of these cytokines. As smoking is well-known risk factor both periodontal disease and adverse pregnancy outcome, only nonsmoking postpartum women of similar socioeconomic level were included to limit potential confounding factors. The aim of this study was to evaluate IL-1 $\beta$ and IL-1ra in GCF and serum (S) levels in nonsmoking women with NB, PLBW, and IUGR.

\section{MATERIALS AND METHODS}

\section{Study groups}

In this unmatched case-control study design, NB group included 64 women who delivered an infant with a birth weight superior to $2500 \mathrm{~g}$ and completed 37 weeks' gestation. PLBW group consisted of 45 mothers who delivered a baby with weighing under $2500 \mathrm{~g}$ and had not completed 37 weeks. IUGR group included 47 mothers who completed 37 weeks of gestation. The criteria for inclusion were: Women aged 18-35 years, singleton pregnancies and subjects with at least 20 noncrowned teeth excluding third molars. Exclusion criteria were: Current/past use of tobacco (smoking/smokeless) and alcohol, history of high-risk gestation, hypertension, gestational diabetes, any systemic disease, and placenta previa. Maternal, obstetric and demographic factors such as maternal age, maternal education, regular prenatal care, genitourinary tract infections during pregnancy, total number of births, previous PLBW, and use of antibiotic during pregnancy period were also recorded. This study was conducted between January 2004 and June 2004 in The Ministry Health of Turkey, Konya Dr. Faruk Sükan Maternity and Childbirth Hospital. The hospital was visited on 2 days/week regular basis. A total of 156 volunteer mothers was selected within $24 \mathrm{~h}$ of delivery according to accessibility and availability of women in the postpartum period. After being informed about the objective and methods of this study, participants signed an informed consent form. This study was approved by the Ethics Committee of Konya Selcuk University Dental Faculty (project number: 04/01).

\section{Clinical periodontal examination}

The periodontal examination was performed with the woman supine on a hospital bed. Full-mouth periodontal examination was performed by the same calibrated investigator (NAK). Measurements of probing depth (PD) and clinical attachment loss (CAL) were made six sites for tooth using William's periodontal probe (Hu-Fredy, Chicago, IL, USA). The PD was recorded at each location as the distance from the gingival margin to the most apical extent of probe penetration. Clinical attachment levels were determined using the cemento-enamel junction as a reference point. PD and CAL measurements were recorded to the nearest higher millimeter using a periodontal probe. The plaque index $(\mathrm{PI})^{[16]}$ and papillary bleeding index $(\mathrm{PBI})^{[17]}$ were also recorded. 
Kayar, et al:: Interleukin-1ra in nonsmoking women with PLBW and IUGR

\section{Biochemical analysis of gingival crevicular fluid and serum samples}

The mesio- and disto-buccal interproximal sites of first molar and incisor tooth in the upper jaw were selected for GCF sampling. A total of two examination sites showing signs of gingival inflammation was sampled in each patient. The crevicular site was the gently dried with cotton pellets. GCF was collected with a Periopaper strip (GCF strips, Proflow Incorpareted, NY, USA) inserted into the sulcus until mild resistance was felt for $30 \mathrm{~s}^{\left[{ }^{18]}\right.}$ Periopaper strips from the two sampling sites of each patient were kept eppendorfs containing $500 \mu \mathrm{l}$ phosphate buffered saline and stored at $-80^{\circ} \mathrm{C}$ until assay. At the time of analysis, the eppendorfs were vortexed to maintain elution of GCF from the strips at room temperature.

Following the oral examination, a peripheral blood sample was obtained from each subject with venipuncture using tubes, which contain spray-coated silica and a polymer gel for serum separation (BD Vacutainer ${ }^{\circledR} S S T^{\mathrm{TM}}$, Diagnostic Preanalytical System, UK). The sample was centrifuged at $2500 \mathrm{rpm}$ for $15 \mathrm{~min}$, and the serum obtain was dissociated in a plastic tube. The tubes were stored at $-80^{\circ} \mathrm{C}$ until analysis.

Gingival crevicular fluid and serum levels of IL-1 $\beta$ and IL-1ra were analyzed with enzyme immunoassay (Cayman Chemical Co., USA) and ELISA (BioSource Europe, Belgium) methods, respectively. Results were calculated using the standard curves created for each assay. Concentrations of the serum cytokines were defined as $\mathrm{pg} / \mathrm{ml}$. The total amount of cytokines in GCF was calculated and expressed as picograms in $30 \mathrm{~s}$ (pg/30 s).

\section{Statistical analysis}

Post-hoc power calculations were performed at the 0.25 significance level. The sample size was calculated using $\alpha=0.05$ and the post-hoc power $=79 \%$. Mean values for all clinical parameters were calculated for each group. The Chi-square test was used to analyze differences in demographic and obstetric characteristics of the study groups. The decision about whether to use parametric or nonparametric tests was made based on the results of Kolmogorov-Smirnov test for a normal distribution. The mean age, PI scores and GCF, and serum levels of IL-1ra were compared between NB, PLBW, and IUGR groups with variance analysis and Tukey HSD test. Kruskal-Wallis and the Bonferroni adjusted Mann-Whitney $U$-tests were used for the analysis of PBI, PD, CAL, and IL-1 $\beta$ values.

\section{RESULTS}

Demographic characteristics for the women are presented in Table 1. The majority of the patients belonged to the lower socioeconomic class in our study. The variable maternal education level showed similar frequencies in all of the women $(P>0.05)$, whereas mean values of age in women with IUGR were higher than NB $(P<0.05)$.

The mean and standard deviations of the full mouth clinical periodontal parameters in NB, PLBW, and IUGR groups are documented in Table 2. PD and CAL scores in PLBW and IUGR groups were higher than NB $(P<0.05)$. Table 3 shows that PI, PBI, CAL levels in GCF sampling areas were not different for NB, PLBW, and IUGR groups $(P>0.05)$, except for PD scores $(P<0.05)$.

Table 4 gives the results of the serum and GCF biochemical parameters in study groups. Total amount of GCF IL-1 $\beta$ (IL-1 $\beta$ GCF) in NB group were higher than PLBW and IUGR group $(P<0.05)$. There were significant differences in amounts of GCF IL-1ra (IL-1ra GCF) between NB, PLBW and IUGR group $(P<0.05)$. Although chromogenic ELISA substrates of IL-1 $\beta$ were detected with standard absorbance plate, the serum IL-1 $\beta$ (IL-1 $\beta^{\mathrm{S}}$ ) concentrations were below the detection limits and we were not able to measure the concentration of IL- $1 \beta^{S}$ in any of the serum samples. The least amount of IL-1ra GCF was found in IUGR group. No significant differences in concentration of IL-1ras were determined in any of the study groups $(P>0.05)$.

\section{DISCUSSION}

The results of this case-control study support the hypothesis that maternal periodontal infection provides an enhanced risk for adverse pregnancy outcomes has been examined using various clinical research designs. During the 6-month period of data collection, a total of 156 postpartum women was participated in this study. To the best of our knowledge, this is the first study demonstrating detected IL-1ra levels in GCF and serum in nonsmoking women within $24 \mathrm{~h}$ of delivery. Low levels of IL-1ra in GCF were observed in PLBW and IUGR group, and the least receptor antagonist amounts in GCF were found in IUGR group. Greater amounts of IL-1 $\beta$ in GCF were found in NB group than PLBW and IUGR. The serum levels of IL-1ra in were found similar for all study groups.

It is well-known that smoking, ethnicity, low educational, and socioeconomic levels were also major risk factors for 
periodontal diseases ${ }^{[1,20]}$ and may confound the association between periodontitis and LBW. ${ }^{[5,7,11,21]}$ Thus, smokers were excluded from the present study. The women in our groups were similar and relatively homogenous based on the low educational and socioeconomic factors.

As the maternal age has been regarded as one of the risk factor for PLBW, ${ }^{[22]}$ we selected the subjects aged 18-34 years. In our study, maternal age in IUGR group was significantly higher than NB. Our study found a significant correlation between advanced maternal age and adverse pregnancy outcomes.

The severe acute infectious diseases, such as pyelonephritis, ${ }^{[23]}$ candidal infections ${ }^{[24]}$ can lead to perinatal and maternal complications including premature delivery, infants with LBW and fetal mortality. We did not observe genitourinary tract

\begin{tabular}{|c|c|c|c|c|c|c|}
\hline & \multicolumn{3}{|c|}{$n \%$} & \multirow[t]{2}{*}{ Statistic } & \multirow[t]{2}{*}{ SD } & \multirow[t]{2}{*}{$P$} \\
\hline & NB $(n=64)$ & PLBW $(n=45)$ & IUGR ( $n=47)$ & & & \\
\hline Age (mean $\pm S D)$ & $21.34 \pm 2.65^{c}$ & $22.53 \pm 3.56$ & $23.23 \pm 4.35$ & $F=4.15$ & 2 & 0.018 \\
\hline \multicolumn{7}{|c|}{ Education level $n(\%)$} \\
\hline None & $2(3.10)$ & $4(8.90)$ & $3(6.40)$ & $\chi^{2}=16.66$ & 6 & 0.070 \\
\hline Primary & $44(68.80)$ & $18(40.00)$ & $32(68.10)$ & & & \\
\hline Secondary & $10(15.90)$ & $11(24.40)$ & $6(12.80)$ & & & \\
\hline Tertiary & $8(12.50)$ & $12(26.70)$ & $6(12.80)$ & & & \\
\hline \multicolumn{7}{|c|}{ Regular prenatal care } \\
\hline Yes & $45(70.3)$ & $20(44.4)$ & $18(38.3)$ & $\chi^{2}=13.10$ & 2 & 0.010 \\
\hline No & $19(29.7)^{*}$ & $25(55.6)$ & $29(61.7)$ & & & \\
\hline \multicolumn{7}{|c|}{ Genitourinary tract infections } \\
\hline Yes & $11(17.2)$ & $4(8.9)$ & $4(8.5)$ & $\chi^{2}=2.54$ & 2 & 0.280 \\
\hline No & $53(82.8)$ & $41(91.1)$ & $43(91.5)$ & & & \\
\hline \multicolumn{7}{|c|}{ Total number of births } \\
\hline One & $39(60.9)$ & $30(66.7)$ & $31(66.0)$ & $\chi^{2}=7.39$ & 4 & 0.116 \\
\hline Two & $17(26.6)$ & $11(24.4)$ & $5(10.6)$ & & & \\
\hline Three and more & $8(12.5)$ & $4(8.9)$ & $11(23.4)$ & & & \\
\hline \multicolumn{7}{|l|}{ Previous PLBW } \\
\hline Yes & $6(9.4)^{*}$ & $11(24.4)$ & $13(27.7)$ & $\chi^{2}=6.94$ & 2 & 0.031 \\
\hline No & $58(90.6)$ & $34(75.6)$ & $34(72.3)$ & & & \\
\hline \multicolumn{7}{|c|}{ Use of antibiotic during pregnancy period } \\
\hline Yes & $19(29.7)^{\star}$ & $5(11.1)$ & $7(14.9)$ & $\chi^{2}=6.77$ & 2 & 0.034 \\
\hline No & $45(70.3)$ & $40(88.9)$ & $40(85.1)$ & & & \\
\hline
\end{tabular}

\begin{tabular}{|c|c|c|c|c|c|}
\hline & NB $(n=64)$ & PLBW $(n=45)$ & lugr ( $n=47)$ & Statistic & $P$ \\
\hline $\mathrm{PI}$ & $2.25 \pm 0.48$ & $2.37 \pm 0.49$ & $2.29 \pm 0.64$ & $F=0.649$ & 0.524 \\
\hline PBI & $1.13 \pm 0.95$ & $1.38 \pm 0.87$ & $1.33 \pm 0.88$ & $\mathrm{~K}-\mathrm{W}=2.802$ & 0.246 \\
\hline PD (mm) & $2.59 \pm 0.92$ & $3.07 \pm 0.66^{\mathrm{a}}$ & $3.10 \pm 0.80^{\mathrm{a}}$ & $K-W=10.682$ & 0.005 \\
\hline \multicolumn{6}{|l|}{ PD (\%) } \\
\hline $0-3(\mathrm{~mm})$ & $74.99 \pm 27.21$ & $70.86 \pm 25.78$ & $70.63 \pm 22.04$ & $K-W=3.379$ & 0.185 \\
\hline $4-5(\mathrm{~mm})$ & $22.89 \pm 19.37$ & $25.78 \pm 18.70^{a}$ & $24.35 \pm 17.25^{a}$ & $K-W=5.659$ & 0.059 \\
\hline$\geq 6(\mathrm{~mm})$ & $2.12 \pm 3.63$ & $3.36 \pm 4.94$ & $5.02 \pm 7.89$ & $K-W=5.493$ & 0.064 \\
\hline $\mathrm{CAL}(\mathrm{mm})$ & $0.933 \pm 1.14$ & $1.81 \pm 1.56^{\mathrm{a}}$ & $1.88 \pm 1.82^{\mathrm{a}}$ & $K-W=14.164$ & 0.001 \\
\hline \multicolumn{6}{|l|}{ CAL $(\%)$} \\
\hline $0(\mathrm{~mm})$ & $78.06 \pm 27.42$ & $58.09 \pm 35.59^{a}$ & $57.85 \pm 38.69^{a}$ & $K-W=14.053$ & 0.001 \\
\hline $1-3(\mathrm{~mm})$ & $8.05 \pm 12.99$ & $16.47 \pm 17.58^{a}$ & $13.40 \pm 14.74^{a}$ & $K-W=9.444$ & 0.009 \\
\hline $4-5(\mathrm{~mm})$ & $11.56 \pm 15.00$ & $21.45 \pm 19.18^{a}$ & $20.77 \pm 19.72^{a}$ & $K-W=10.464$ & 0.005 \\
\hline$\geq 6(\mathrm{~mm})$ & $2.33 \pm 5.08$ & $3.99 \pm 6.33$ & $7.98 \pm 13.46^{a}$ & $K-W=10.358$ & 0.006 \\
\hline
\end{tabular}


infection during pregnancy in all of the study groups and did not appear as a risk factor for pregnancy. It might be related with infection type and/or use of antibiotics during pregnancy.

In this study, use of antibiotics in pregnancy was at greater levels in NB than PLBW and IUGR group. But, the use of antibiotics in pregnancy appears to be significantly associated with an increased rate in the incidence of $\mathrm{NB}$, confirming results from several other studies. ${ }^{[12,25]}$

We also demonstrated that the risk of PLBW and IUGR was increased in women who have irregular prenatal care during pregnancy and history of adverse pregnancy outcomes. Monitoring the course of pregnancy, in order to promote favorable outcomes improve pregnancy outcomes. ${ }^{[2]}$

Our results were consistent with concurrent studies demonstrating dose-dependent relationship between increasing periodontal disease severity and an increase in the rate of PLBW, ${ }^{[5,12,21]}$ whereas no significant association was found between periodontal tissue destruction and PLBW..$^{[3,27]}$ In our study, we observed a high level PI and PBI scores in all of the women in the postpartum period. The mean values of CAL and PD, especially numbers of sites with 4-5 mm PD measurements in NB group were lower than PLBW and IUGR groups. Periodontal tissue destruction with deep periodontal pockets may serve as a reservoir for bacterial colonization, and host defenses may be changed related to the individual factors of host response (such as genetic and environmental risks.). We thought that maternal periodontal disease may be associated with impair fetal growth and prematurity in postpartum women.

Cross-sectional and longitudinal studies have reported increased IL-1 $\beta$ levels in GCF in periodontal tissue destruction sites, ${ }^{[28-30]}$ whereas on study conducted by Rawlinson et al..$^{[15]}$ demonstrated that GCF levels of IL-1 $\beta$ from healthy sites were greater than deep periodontal pockets in nonpostpartum patients. Interestingly, our findings of lower total amounts of IL-1 $\beta$ at deep pockets for PLBW and IUGR group in comparison with NB is in contrast to previous postpartum studies, which generally report a correlation between severity of inflammation and increasing concentrations of IL- $1 \beta$ in women with PLBW. ${ }^{[7,10]}$ However, Offenbacher et al ${ }^{[5]}$ reported that GCF concentrations of IL-1 $\beta$ were not statistically significantly different in women with NB and PLBW. Noack et al. ${ }^{[13]}$ showed tendency for increasing IL-1 $\beta$ concentrations in women with PLBW with decreasing mean PD scores. Various results in the literature could be due to different study groups, collection time of GCF sampling and evaluation of the total amounts or concentration of cytokine levels. In contrast to other studies, ${ }^{[5,7,10,13]}$ we collected GCF with paper strips in $30 \mathrm{~s}$. The total amount of cytokines in GCF sample per sampling time has been suggested as a better indicator of relative GCF constituent activity rather than the GCF volume that might result in the decrease of the cytokine concentration. ${ }^{[31]}$ Furthermore, differences between the study population in our study and that of the other studies ${ }^{[5,7,10,13]}$ include smoking and the evaluation time after delivery. Smoking may be an important factor for the periodontal disease ${ }^{[32,33]}$ and preterm labor. ${ }^{[12,34]}$ However, conflicting results were published from authors regarding the effects of smoking on IL-1 $\beta^{[15,29]}$ in nonpostpartum subjects. No association between IL-1 $\beta$ and smoking status has been observed, ${ }^{[28,29]}$ as well as lower IL-1 $\beta$ levels of GCF in smokers as compared nonsmokers. ${ }^{[15]}$ Therefore, our study population consisted of nonsmoker patients diverging from other postpartum studies..$^{[5,7,10,13]}$ It is

\begin{tabular}{|c|c|c|c|c|c|}
\hline & $\begin{array}{c}\text { NB } \\
(n=64)\end{array}$ & $\begin{array}{l}\text { PLBW } \\
(n=45)\end{array}$ & $\begin{array}{l}\text { IUGR } \\
(n=47)\end{array}$ & Statistic & $P$ \\
\hline PI & $2.46 \pm 0.52$ & $2.51 \pm 0.63$ & $2.44 \pm 0.50$ & $F=0.173$ & 0.841 \\
\hline PBI & $1.36 \pm 1.10$ & $1.68 \pm 0.89$ & $1.65 \pm 0.89$ & $K-W=3.501$ & 0.174 \\
\hline PD & $3.57 \pm 1.56$ & $4.29 \pm 1.34^{a}$ & $4.43 \pm 1.43^{a}$ & $\mathrm{~K}-\mathrm{W}=10.444$ & 0.005 \\
\hline CAL & $1.99 \pm 2.12$ & $2.72 \pm 2.38$ & $2.84 \pm 2.52$ & $K-W=4.510$ & 0.105 \\
\hline
\end{tabular}

$F$ : Results of variance analysis, K-W: Results of Kruskal-Wallis analysis. acompared to the NB $(P<0.05)$ (Kruskal-Wallis test followed by the Bonferroni correction of the Mann-Whitney U-test). GCF: Gingival crevicular fluid, NB: Normal birth, PLBW: Preterm low birth weight, IUGR: Intrauterine growth retardation, PI: Plaque index, PBI: Papillary bleeding index, PD: Probing depth, CAL: Clinical attachment loss, SD: Standard deviation

\begin{tabular}{|c|c|c|c|c|c|}
\hline & NB $(n=64)$ & PLBW $(n=45)$ & IUGR ( $n=47)$ & Statistic & $P$ \\
\hline $\mathrm{IL}-1 \beta^{\mathrm{GCF}}(p g / 30 \mathrm{~s})$ & $85.07 \pm 77.19$ & $48.97 \pm 73.71^{a}$ & $39.32 \pm 70.76^{c}$ & $K-W=31.205$ & 0.000 \\
\hline IL-1ra ${ }^{G C F}(p g / 30 ~ s)$ & $721.10 \pm 38.27$ & $702.49 \pm 36.00$ & $682.61 \pm 31.55^{a, b}$ & $F=15.789$ & 0.000 \\
\hline IL-1ras (pg/ml) & $205.72 \pm 71.51$ & $214.32 \pm 98.88$ & $189.24 \pm 79.78$ & $F=2.691$ & 0.260 \\
\hline
\end{tabular}

K-W: Results of Kruskal-Wallis analysis. ${ }^{a}$ compared to the NB $(P<0.05)$, ${ }^{b}$ Compared to the PLBW $(P<0.05)$ (Kruskal-Wallis test followed by the Bonferroni correction of the Mann-Whitney U-test), ${ }^{\circ}$ compared to the NB $(P<0.05)$ (variance analysis followed by Tukey HSD). $F$ : Results of variance analysis, NB: Normal birth, PLBW: Preterm low birth weight, IUGR: Intrauterine growth retardation, IL: Interleukin 
known that the fetal endocrine changes lead to birth result in increased maternal estrogen production and stimulation of effective uterine contractility and dilation of the cervix. ${ }^{[35]}$ Payne et al. ${ }^{[36]}$ demonstrated that greater amounts of IL- $1 \beta$ in GCF were found in estrogen-deficient patients than estrogen-sufficient patients. It can be speculated that the increased estrogen and progesterone levels after postal period in both PLBW and women with IUGR may lead to decrease in IL-1 $\beta$ levels.

IL-1ra is mainly produced by neutrophils and macrophages, which has been shown to inhibit the IL-1 $\beta$ activity by binding and blocking the specific receptors for IL-1 $\beta$ found on the target cells. ${ }^{[37]}$ IL-1ra is an interesting cytokine and GCF concentrations of IL-1ra were found higher in deep pocket sites ${ }^{[14,29]}$ than shallow pockets, whereas the others did not find positive correlation between tissue destruction and IL-1ra levels in GCF. ${ }^{[15,38]}$ But exact role of GCF IL-1ra in periodontal tissue destruction is not completely understood. The observations regarding IL-1ra concentrations in GCF, which is involved in the control of the production and activity of IL- $1 \beta$, suggest that decreased amounts of IL-1ra in GCF may be related to PLBW and especially, IUGR.

Although there were many studies about serum levels of IL- $1 \beta$ in nonpostpartum patients, but the assessment of IL-1 $\beta$ concentrations have some technique problems: The concentration of IL-1 $\beta$ was detected in all patients ${ }^{[12,39]}$ or may be lower levels than detection limits in some of the serum samples. ${ }^{[00-43]}$ Only one study in literature regarding IL-1 $\beta$ levels of serum in postpartum women was conducted by Konopka et al. ${ }^{[7]}$ After stimulated whole blood by bacterial lipopolysaccharide, they measured the concentrations of serum IL-1 $\beta$ in only three samples of PLBW postpartum women (3.5\%). In our study, we were unable to demonstrate serum levels of IL-1 $\beta$ in any of the study groups. We did not find that of the local production of IL-1 $\beta$ in periodontal tissues may reach elevated levels in the maternal serum and stimulate premature uterine contractions.

The concentration of IL-1ra was found 10-100 fold higher levels than IL-1 $\beta$ in body fluids, ${ }^{[43]}$ and therefore, it has been suggested that IL-1ra may be used as a marker of disease. The results from nondental studies according serum IL-1ra levels in humans have not uniformly been in agreement; some have yielded null findings ${ }^{[4,45]}$ and others observed an anti-inflammatory effect of IL-1ra. ${ }^{[46-49]}$ Serum levels of IL-1ra are increased in patients with obesity, impaired glucose tolerance and metabolic syndrome regarding their anti-inflammatory effect, ${ }^{[46-49]}$ and decreased in patients with sepsis and septic shock ${ }^{[50]}$ related with organ failure and maternal complications in postpartum period. ${ }^{[51]}$ It has been suggested that any infection of the amniotic fluid will trigger the proinflammatory cytokine cascade resulting in intrauterine contractions and preterm labor. ${ }^{[52]}$ However, the data presented by Holcberg et al. ${ }^{[50]}$ indicate that no significant differences were observed in the release of IL-1ra into the maternal and fetal compartments of term placenta, when compared to preterm placenta. Witkin et al. ${ }^{[6]}$ found no significant relationship between the amniotic concentrations of IL-1ra and IL-1 $\beta$ levels and preterm birth. In current study, we did not examine the amniotic levels of the cytokines. Within the limitation of this study, we demonstrated that the concentrations of serum IL-1ra were similar in NB, PLBL, and IUGR groups.

\section{CONCLUSIONS}

We showed that greater periodontal tissue destruction was found in women with PLBW and IUGR than women with NB. On the other hand, the results of this study do not support the hypothesis of serum cytokine concentrations is associated with an increased risk of PLBW and IUGR. Within limitation of this study, it can be concluded that there was an association with decreasing IL-1ra total amounts in GCF and worse periodontal conditions in nonsmoking women with PLBW and IUGR, despite to the low levels of IL-1 $\beta$ in GCF in both of these two groups. Further studies are needed to clarify the possible relationship between local or systematical proinflammatory and anti-inflammatory cytokine levels, hormonal changes, genetic polymorphisms, and poor obstetric outcomes.

\section{ACKNOWLEDGMENTS}

This study was partly supported by Selcuk University Scientific Research Center (Project number (2001/104). The authors thank to Prof.Said Bodur for the statistical analysis of the data.

\section{REFERENCES}

1. McCormick MC. The contribution of low birth weight to infant mortality and childhood morbidity. N Engl J Med 1985;312:82-90.

2. Cheung YF, Wong KY, Lam BC, Tsoi NS. Relation of arterial stiffness with gestational age and birth weight. Arch Dis Child 2004;89:217-21.

3. Bacchetta J, Harambat J, Dubourg L, Guy B, Liutkus A, Canterino I, et al. Both extrauterine and intrauterine growth restriction impair renal function in children born very preterm. Kidney Int 2009;76:445-52.

4. David RJ, Collins JW Jr. Differing birth weight among infants of U.S.-born blacks, African-born blacks, and U.S.-born whites. N Engl J Med 1997;337:1209-14.

European Journal of Dentistry, Vol 9 / Issue 1 / Jan-Mar 2015 
5. Offenbacher S, Jared HL, O'Reilly PG, Wells SR, Salvi GE, Lawrence HP, et al. Potential pathogenic mechanisms of periodontitis associated pregnancy complications. Ann Periodontol 1998;3:233-50.

6. Witkin SS, Vardhana S, Yih M, Doh K, Bongiovanni AM, Gerber S. Polymorphism in intron 2 of the fetal interleukin-1 receptor antagonist genotype influences midtrimester amniotic fluid concentrations of interleukin-1beta and interleukin-1 receptor antagonist and pregnancy outcome. Am J Obstet Gynecol 2003;189:1413-7.

7. Konopka T, Rutkowska M, Hirnle L, Kopec W, Karolewska E. The secretion of prostaglandin E2 and interleukin 1-beta in women with periodontal diseases and preterm low-birth-weight. Bull Group Int Rech Sci Stomatol Odontol 2003;45:18-28.

8. Lin D, Moss K, Beck JD, Hefti A, Offenbacher S. Persistently high levels of periodontal pathogens associated with preterm pregnancy outcome. J Periodontol 2007;78:833-41.

9. Romero R, Durum S, Dinarello CA, Oyarzun E, Hobbins JC, Mitchell MD. Interleukin-1 stimulates prostaglandin biosynthesis by human amnion. Prostaglandins 1989;37:13-22.

10. Carta G, Persia G, Falciglia K, Iovenitti P. Periodontal disease and poor obstetrical outcome. Clin Exp Obstet Gynecol 2004;31:47-9.

11. Dörtbudak O, Eberhardt R, Ulm M, Persson GR. Periodontitis, a marker of risk in pregnancy for preterm birth. J Clin Periodontol 2005;32:45-52.

12. Hasegawa K, Furuichi Y, Shimotsu A, Nakamura M, Yoshinaga M, Kamitomo M, et al. Associations between systemic status, periodontal status, serum cytokine levels, and delivery outcomes in pregnant women with a diagnosis of threatened premature labor. J Periodontol 2003;74:1764-70.

13. Noack B, Klingenberg J, Weigelt J, Hoffmann T. Periodontal status and preterm low birth weight: A case control study. J Periodontal Res 2005;40:339-45.

14. Ishihara $\mathrm{Y}$, Nishihara T, Kuroyanagi T, Shirozu N, Yamagishi E, Ohguchi M, et al. Gingival crevicular interleukin-1 and interleukin-1 receptor antagonist levels in periodontally healthy and diseased sites. J Periodontal Res 1997;32:524-9.

15. Rawlinson A, Grummitt JM, Walsh TF, Ian Douglas CW. Interleukin 1 and receptor antagonist levels in gingival crevicular fluid in heavy smokers versus non-smokers. J Clin Periodontol 2003;30:42-8.

16. Löe $H$. The gingival index, the plaque index and the retention index systems. J Periodontol 1967;38 Suppl: 610-6.

17. Mühlemann HR. Psychological and chemical mediators of gingival health. J Prev Dent 1977;4:6-17.

18. Chambers DA, Imrey PB, Cohen RL, Crawford JM, Alves ME, McSwiggin TA. A longitudinal study of aspartate aminotransferase in human gingival crevicular fluid. J Periodontal Res 1991;26:65-74.

19. Kramer MS. Determinants of low birth weight: Methodological assessment and meta-analysis. Bull World Health Organ 1987;65:663-737.

20. Kramer MS. Intrauterine growth and gestational duration determinants. Pediatrics 1987;80:502-11.

21. Offenbacher S, Katz V, Fertik G, Collins J, Boyd D, Maynor G, et al. Periodontal infection as a possible risk factor for preterm low birth weight. J Periodontol 1996;67:1103-13.

22. Bettiol H, Rona RJ, Chinn S, Goldani M, Barbieri MA. Factors associated with preterm births in southeast Brazil: A comparison of two birth cohorts born 15 years apart. Paediatr Perinat Epidemiol 2000;14:30-8.

23. Kaul AK, Khan S, Martens MG, Crosson JT, Lupo VR, Kaul R. Experimental gestational pyelonephritis induces preterm births and low birth weights in C3H/HeJ mice. Infect Immun 1999;67:5958-66.

24. Oleszczuk JJ, Keith LG. Vaginal infection: Prophylaxis and perinatal outcome - a review of the literature. Int J Fertil Womens Med 2000;45:358-67.

25. Kazy Z, Puhó EH, Czeizel AE. The possible preterm birth preventive effect of ampicillin during pregnancy. Arch Gynecol Obstet 2006;274:215-21.

26. Aluko JO, Oluwatosin A. Pattern and outcome of antenatal care among women attending a Catholic mission hospital in Ibadan, Nigeria. Afr J Med Med Sci 2008;37:231-8.

27. Buduneli N, Baylas H, Buduneli E, Türkoglu O, Köse T, Dahlen G. Periodontal infections and pre-term low birth weight: A case-control study. J Clin Periodontol 2005;32:174-81.

28. Boström L, Linder LE, Bergström J. Smoking and GCF levels of IL-1beta and IL-1ra in periodontal disease. J Clin Periodontol 2000;27:250-5.

29. Giannopoulou C, Kamma JJ, Mombelli A. Effect of inflammation, smoking and stress on gingival crevicular fluid cytokine level. J Clin Periodontol 2003;30:145-53.

30. Holmlund A, Hänström L, Lerner UH. Bone resorbing activity and cytokine levels in gingival crevicular fluid before and after treatment of periodontal disease. J Clin Periodontol 2004;31:475-82.

31. Gamonal J, Bascones A, Jorge O, Silva A. Chemokine RANTES in gingival crevicular fluid of adult patients with periodontitis. J Clin Periodontol 2000;27:675-81.

32. Ojima M, Hanioka T, Tanaka K, Inoshita E, Aoyama H. Relationship between smoking status and periodontal conditions: Findings from national databases in Japan. J Periodontal Res 2006;41:573-9.

33. Chiou LJ, Yang YH, Hung HC, Tsai CC, Shieh TY, Wu YM, et al. The association of psychosocial factors and smoking with periodontal health in a community population. J Periodontal Res 2010;45:16-22.

34. Shiono PH, Klebanoff MA, Rhoads GG. Smoking and drinking during pregnancy. Their effects on preterm birth. JAMA 1986;255:82-4.

35. Nathanielsz PW, Giussani DA, Mecenas CA, Wu W, Winter JA, Garcia-Villar R, et al. Regulation of the switch from myometrial contractures to contractions in late pregnancy: Studies in the pregnant sheep and monkey. Reprod Fertil Dev 1995;7:595-602.

36. Payne JB, Reinhardt RA, Masada MP, DuBois LM, Allison AC. Gingival crevicular fluid IL-8: Correlation with local IL-1 beta levels and patient estrogen status. J Periodontal Res 1993;28:451-3.

37. Dinarello CA. Interleukin-1 and interleukin-1 antagonism. Blood 1991;77:1627-52.

38. Rawlinson A, Dalati MH, Rahman S, Walsh TF, Fairclough AL. Interleukin-1 and IL-1 receptor antagonist in gingival crevicular fluid. J Clin Periodontol 2000;27:738-43.

39. Guo S, Takahashi K, Kokeguchi S, Takashiba S, Kinane DF, Murayama Y. Antibody responses against Porphyromonas gingivalis infection in patients with early-onset periodontitis. J Clin Periodontol 2000;27:769-77.

40. Albandar JM, DeNardin AM, Adesanya MR, Winn DM, Diehl SR. Associations of serum concentrations of $\operatorname{IgG}, \operatorname{IgA}, \operatorname{IgM}$ and interleukin-1beta with early-onset periodontitis classification and race. J Clin Periodontol 2002;29:421-6.

41. Mengel R, Bacher M, Flores-De-Jacoby L. Interactions between stress, interleukin-1beta, interleukin-6 and cortisol in periodontally diseased patients. J Clin Periodontol 2002;29:1012-22.

42. Orozco A, Gemmell E, Bickel M, Seymour GJ. Interleukin-1beta, interleukin-12 and interleukin-18 levels in gingival fluid and serum of patients with gingivitis and periodontitis. Oral Microbiol Immunol 2006;21:256-60.

43. Michalowicz BS, Novak MJ, Hodges JS, DiAngelis A, Buchanan W, Papapanou PN, et al. Serum inflammatory mediators in pregnancy: Changes after periodontal treatment and association with pregnancy outcomes. J Periodontol 2009;80:1731-41.

44. Schmeelk KH, Granger DA, Susman EJ, Chrousos GP. Maternal depression and risk for postpartum complications: Role of prenatal corticotropin-releasing hormone and interleukin-1 receptor antagonist. Behav Med 1999;25:88-94.

45. Nguyen HB, Loomba M, Yang JJ, Jacobsen G, Shah K, Otero RM, et al. Early lactate clearance is associated with biomarkers of inflammation, coagulation, apoptosis, organ dysfunction and mortality in severe sepsis and septic shock. J Inflamm (Lond) 2010 28;7:6.

46. Meier CA, Bobbioni E, Gabay C, Assimacopoulos-Jeannet F, Golay A, Dayer JM. IL-1 receptor antagonist serum levels are increased in human obesity: A possible link to the resistance to leptin? J Clin Endocrinol Metab 2002;87:1184-8.

47. Salmenniemi U, Ruotsalainen E, Pihlajamäki J, Vauhkonen I, Kainulainen S, Punnonen $\mathrm{K}$, et al. Multiple abnormalities in glucose and energy metabolism and coordinated changes in levels of adiponectin, cytokines, and adhesion molecules in subjects with metabolic syndrome. Circulation 2004 21;110:3842-8.

48. Herder C, Brunner EJ, Rathmann W, Strassburger K, Tabák AG, Schloot NC, et al. Elevated levels of the anti-inflammatory interleukin-1 receptor antagonist precede the onset of type 2 diabetes: The Whitehall II study. Diabetes Care 2009;32:421-3.

49. Hofsø D, Ueland T, Hager H, Jenssen T, Bollerslev J, Godang K, et al. Inflammatory mediators in morbidly obese subjects: Associations with glucose abnormalities and changes after oral glucose. Eur J Endocrinol 2009;161:451-8

50. Holcberg G, Amash A, Sapir O, Sheiner E, Levy S, Myatt L, et al. 
Kayar, et al:: Interleukin-1ra in nonsmoking women with PLBW and IUGR

Perfusion with lipopolysaccharide differently affects the secretion of interleukin-1 beta and interleukin-1 receptor antagonist by term and preterm human placentae. Placenta 2008;29:593-601.

51 Dinarello CA. Biologic basis for interleukin-1 in disease. Blood 1996;87:2095-147.

52. Lo Vasco VR, Cosmi E, Visentin S, Di Raimo T, Salmaso R, Zanardo V, et al. IL-1ß and IL-23 in amniotic fluids of ultrasound-detected aortic intima/media thickness and growth retardation. J Reprod Immunol 2012;93:64-7.

\begin{tabular}{|l|l|}
\hline \multicolumn{2}{|c|}{ Access this article online } \\
\hline Quick Response Code: & Website: \\
\hline & www.eurjent.com \\
\cline { 2 - 2 } & Source of Support: Nil. \\
\hline
\end{tabular}

